Published in final edited form as:

Subst Use Misuse. 2012 September ; 47(11): 1234-1247. doi:10.3109/10826084.2012.700678.

\title{
Knowledge, Attitudes, and Substance Use Practices Among Street Children in Western Kenya
}

\author{
Lonnie Embleton ${ }^{1}$, David Ayuku², Lukoye Atwoli ${ }^{3}$, Rachel Vreeman ${ }^{4,5}$, and Paula \\ Braitstein $1,6,7,8$ \\ ${ }^{1}$ Department of Medicine, College of Health Sciences, School of Medicine, Moi University, \\ Eldoret, Kenya \\ ${ }^{2}$ Department of Behavioral Sciences, College of Health Sciences, School of Medicine, Moi \\ University, Eldoret, Kenya \\ ${ }^{3}$ Department of Mental Health, College of Health Sciences, School of Medicine, Moi University, \\ Eldoret, Kenya \\ ${ }^{4}$ Department of Pediatrics, College of Health Sciences, School of Medicine, Moi University, \\ Eldoret, Kenya \\ ${ }^{5}$ Department of Children's Health Services Research, School of Medicine, Indiana University, \\ Indianapolis, Indiana, USA \\ ${ }^{6}$ Department of Medicine, School of Medicine, Indiana University, Indianapolis, Indiana, USA \\ ${ }^{7}$ Dalla Lana School of Public Health, University of Toronto, Toronto, Ontario, Canada \\ ${ }^{8}$ Regenstrief Institute, Inc., Indianapolis, Indiana, USA
}

\begin{abstract}
The study describes the knowledge of and attitudes toward substance use among street-involved youth in Kenya, and how they relate to their substance use practices. In 2011, 146 children and youth ages 10-19 years, classified as either children on the street or children of the street were recruited to participate in a cross-sectional survey in Eldoret, Kenya. Bivariate analysis using $\chi^{2}$ or Fisher's Exact Test was used to test the associations between variables, and multiple logistic regression analysis was used to identify independent covariates associated with lifetime and current drug use. The study's limitations and source of funding are noted.
\end{abstract}

\section{Keywords}

substance use; street children; resource-constrained; knowledge; attitudes; inhalants

\section{INTRODUCTION}

Kenya has an estimated 250,000 to 300,000 streetinvolved children and youth (IRIN, 2007) and worldwide it is estimated tens of millions of children are involved in street life (UNICEF, 2006). These children spend either a portion or majority of their time on the street

Copyright (C) 2012 Informa Healthcare USA, Inc.

Address correspondence to Dr. Paula Braitstein, School of Medicine, Indiana University, 1001 West 10th Street, OPW M200, Indianapolis, IN 46202, USA; pbstraistein@yahoo.com.

Declaration of Interest

All authors declare that they have no conflicts of interest. The authors alone are responsible for the content and writing of the article. 
engaging in activities to generate income that often involve child abuse and exploitation (Bal, Mitra, Mallick, Chakraborti, \& Sarkar, 2010), while falling into patterns of substance use (Bal et al., 2010; Morakinyo \& Odejide, 2003; Njord, Merrill, Njord, Lindsay, \& Pachano, 2010; Towe, ul Hasan, Zafar, \& Sherman, 2009).

Children in resource-constrained settings succumb to street life due to abject poverty, child abuse, neglect, familial dysfunction, death of one or both of the parents, war, sociocultural and religious beliefs, among other reasons (Abdelgalil, Gurgel, Theobald, \& Cuevas, 2004; Ayaya \& Esamai, 2001; Ayuku, Odero, Kaplan, De Bruyn, \& De Vries, 2003; de Carvalho et al., 2006; Njord et al., 2010; Plummer, Kudrati, \& Dafalla El Hag Yousif, 2007; Towe et al., 2009). Children living and working on the street fall into one of two categories: children of the street or children on the street. Children on the street spend a portion of their time on the street, either roaming or working to provide an economic contribution to their family. These children often return home at night to sleep, maintaining familial ties. Children of the street both work and sleep on the streets and have an absence of regular contact with family members (Ayuku, Kaplan, Baars, \& de Vries, 2004; Ayuku et al., 2003; Fernandes \& Vaughn, 2008; Kaime-Atterhög \& Ahlberg, 2008; le Roux, 1996; Plummer et al., 2007; Von Acker, Oosrrom, Rorh, \& De Kemp, 1999). Both groups of street children are stigmatized and vulnerable to a wide range of physical and mental health problems (Ayaya \& Esamai, 2001; de Carvalho et al., 2006; Fernandes \& Vaughn, 2008; Morakinyo \& Odejide, 2003).

Substance use is a major issue among street-involved children and youth worldwide. A lack of sensitization, resources, and services available to assist children in street circumstances in low-to-middle income countries are particularly alarming given the high prevalence: studies from Latin America, Africa, the Middle East, and Asia have reported substance use among street children ranging from $40 \%$ to $84 \%$ (Adebiyi, Owaoje, \& Asuzu, 2008; Bal et al., 2010; de Carvalho et al., 2006; Gaidhane et al., 2008; Inciardi \& Surratt, 1998; Khurana, Sharma, Jena, Saha, \& Ingle, 2004; Morakinyo \& Odejide, 2003; Nada \& Suliman, 2010; Pagare, Meena, Singh, \& Saha, 2004; Sherman, Plitt, ul Hassan, Cheng, \& Zafar, 2005; Sorsa, Kidanemariam, \& Erosie, 2002). Although overall prevalence and type of substance use varies by region, inhalants are consistently used at extremely high rates $(31 \%-100 \%)$ by children in street circumstances in resource-constrained settings (Ayaya \& Esamai, 2001; Bal et al., 2010; Baldivieso, 1995; Carlini-Cotrim, 1995; Elkoussi \& Bakheet, 2011; Forster, Tannhauser, \& Barros, 1996; Kudrati, Plummer, \& Yousif, 2008; Lerner \& Ferrando, 1995; Njord et al., 2010; Sharma \& Lal, 2011; Wittig, Wright, \& Kaminsky, 1997).

Short- and long-term negative physical and mental health effects of using inhalants include cognitive and neurological impairment, teratogenic effects, sudden sniffing death syndrome due to cardiac arrhythmia, and renal, hepatic, and pulmonary damage (Kurtzman, Otsuka, \& Wahl, 2001; Sherman et al., 2005). Additionally, evidence of psychological addiction and dependence has been reported (Kudrati et al., 2008; Seth, Kotwal, \& Ganguly, 2005). Given the high burden of street-involved children and youth in low-to-middle income countries using inhalants, evidence is urgently needed to inform public health programs and policies aimed at preventing, treating, and reducing the harms associated with substance use among this extremely vulnerable and largely neglected population. The primary objective of this study is to describe the knowledge of and attitudes toward substance use among a community-based sample of street-involved children and youth ages 10-19 years in western Kenya, and how their knowledge and attitudes relate to their substance use practices. 


\section{METHODOLOGY}

\section{Study Setting}

Eldoret is a town in western Kenya and is the administrative center of the Uasin Gishu County of Rift Valley Province. It is home to Moi University (including Kenya's second medical school), Moi Teaching and Referral Hospital (MTRH), and the USAID-AMPATH Partnership (Ayaya \& Esamai, 2001; Einterz et al., 2007). With a total population of 289,380, it is currently the fifth largest city in the country (Kenya Open Data Project., 2011) and is located within the most rapidly urbanizing region of the world (UNHABITAT, 2008). Rapid urbanization and rural-to-urban migration has resulted in the development of many informal settlements surrounding the town; $51.3 \%$ of the population in Uasin Gishu County live below the Kenya poverty line, and approximately $52 \%$ of the population are below the age of 20 (Kenya Open Data Project, 2011).

\section{Study Population}

Postelection violence, rapid urbanization, abject poverty, and HIV/AIDS have contributed to the existence of children on the streets of Eldoret (Ayaya \& Esamai, 2001; Ayuku, Ettyang, \& Odero, 2004; Ayuku et al., 2003; Cottrell-Boyce, 2010). Street children in Eldoret were first reported in 1989, with numbers increasing substantially around 1991-1992 and 20072008 in the wake of postelection violence due to internal displacement that resulted in large numbers of families migrating into impoverished urban slums surrounding the town (Ayaya \& Esamai, 2001; Ayuku, Kaplan, et al., 2004; Cottrell-Boyce, 2010). Displacement for many families resulted in loss of property, thereby leaving them destitute (Ayuku, Kaplan, et al., 2004). Many children living in poverty stricken settlements subsequently became streetinvolved, due to the difficult living situations they found themselves in (Ayuku, Kaplan, et al., 2004; Ayuku et al., 2003). Previous research in Eldoret found that street children lack a balanced social network, social support services, and do not have an adequate relationship with an adult caregiver, leaving them without their psychosocial needs fulfilled (Ayuku, Kaplan, et al., 2004). However, despite the lack of social support, these children are highly resilient, have a strong peer network, and adapt easily to their environments (Ayuku, Devries, Mengech, \& Kaplan, 2004).

\section{Eligibility}

Children and youth aged 10-19 classified as either children on the street or children of the street were recruited through street outreach to participate in a cross-sectional survey from May to July, 2011, at MTRH in Eldoret, Kenya. Street-involved children and youth were eligible to participate if they were between the ages of 10 and 19 and not currently enrolled in an educational institution and either (a) spending a portion or majority of their time on the street working or roaming while returning to sleep with family or a guardian at night (child on the street) or (b) having limited or no contact with family and spending both days and nights living and sleeping on the streets or in a shelter (child of the street).

\section{Recruitment and Enrolment}

Extensive street outreach and study sensitization occurred in the "bases/barracks" (primary locations in which street children reside) in Eldoret town. An existing relationship between the research team and a number of street-involved children and youth in Eldoret assisted in identification and outreach within these locations. An outreach worker with experience working with this population was engaged to conduct the outreach and provide information about the study. During outreach sessions, conducted both individually and with groups, the purpose of the study was explained and children were invited to participate voluntarily in the investigation. Eligible children and youth were also identified and recruited through their 
peers using snowball sampling until the required calculated sample size $(N=146)$ was reached. The survey was conducted at a study clinic on the grounds of MTRH that is dedicated to research with vulnerable children. The study clinic provided a neutral, safe, and private location that street-involved children felt comfortable attending to discuss substance use. Children and youth gave their assent and enrolled via the project social worker at a study clinic.

\section{Protection of Human Subjects}

This study received ethical approval from the Indiana University Institutional Review Board, the University of Toronto Research Ethics Board, and the Moi University/Moi Teaching and Referral Hospital Institutional Research Ethics Committee. Approval for the study was also provided by the District Children's Officer, and we obtained a waiver of individual guardian consent because as per human subjects regulations, the study was minimal risk, the study could not have been practicably carried out without the waiver, and because the waiver did not adversely alter the risk-benefit ratio for participants. Individual written assent was obtained from each participant. Assent was obtained by a social worker trained in assenting vulnerable populations (especially children). Children requesting or requiring healthcare but who were not eligible to participate in the study or who refused to provide assent were provided with healthcare services without enrolment into the study.

\section{Data Collection}

A cross-sectional survey was designed within the Knowledge, Attitudes and Practices (KAP) model. The KAP model seeks to comprehend what is known, believed, and done in a specific population in relation to a particular topic in order to inform program development and interventions that are contextually and culturally appropriate (Medicins du Monde, 2011; WHO, 2008). The survey was conducted in Kiswahili through face-to-face interviews using a questionnaire comprised of 78 questions. Prior to the study commencing, the survey was translated into Kiswahili. However, many street-involved children and youth utilize a street language known as "Sheng" and do not adequately comprehend traditional Kiswahili. Therefore, the questionnaire was administered at the study clinic located at MTRH by a trained (Kenyan) research assistant (fluent in English, Kiswahili, and Sheng) and the principal investigator using oral translation from English into Kiswahili/Sheng. Responses and interview data were recorded in English on the questionnaire by the research assistant. A preliminary version of this questionnaire was piloted using 52 questions at a street children's drop-in center in Eldoret, Kenya, to evaluate changes in knowledge, attitudes, and practices of street-involved children and youth participating in a substance abuse curriculum. The questionnaire was subsequently modified to ascertain additional in-depth information concerning substance use practices and demographics of the participants.

\section{Study Outcomes and Variables}

The primary outcomes of interest were (1) having any lifetime drug use versus never having used drugs and (2) currently using drugs (use within the past month) versus never having used and/or not currently using. Drug use variables included any lifetime use (even once), current drug use (defined as any substance use during the past month), frequency of drug use (daily/weekly or less), types of drugs ever and currently used, money spent per day on drugs, age of first drug use, age started using regularly (defined as at least once per month), reasons for using, ever exchanging or selling sex to obtain drugs (yes/no), ever engaging in sexual activity while on drugs (yes/no), and ever engaging in unprotected sex while on drugs (yes/no). To note, the drug miraa (also known as $K h a t$ ), is a naturally occurring plant that contains the active ingredient cathinone and acts as a stimulant when consumed. Glue sniffing in Eldoret involves the inhalation of a synthetic adhesive that is a toluene-based volatile solvent used by cobblers in the repair and making of shoes. 
The survey collected data concerning sociodemographics, drug use characteristics, and knowledge and attitudes about drug use. Sociodemographics documented were age, sex, highest education level attended (<primary [nursery], primary, secondary, no formal education), any family contact (yes/no), frequency of family contact (daily/weekly or less), whether a family member used drugs or alcohol (including tobacco) (yes, no/don't know), where the participant stays at night (with family, a shelter, on the streets, or in the barracks), how often coming to the streets (daily/weekly or less), length of time on the street $(<1$ year, $1-2$ years, $>2$ years), income generating activities (yes/no), money earned per day $(<100$ Kenyan Shillings [KES], >100 KES), and whether children had accessed services for street children (yes, no/don't know). Any family contact included contact with mother, father, grandparents, aunt, uncle, siblings, and cousins. A shelter was defined as a communally rented space among a group of street children/youth in a low to very-low income area of Eldoret. Accessing services for street children in Eldoret was defined as attending any of the organizations that regularly provide basic support services such as feeding, bathing, and informal education. Using participant responses to questions about where they stay at night and family contact we categorized participants into children of the street and children on the street.

Knowledge and attitudes were assessed by asking questions about whether they had ever been taught the dangers of using drugs (yes/no), if they were aware of the harms of using drugs (strongly agree/agree, disagree/strongly disagree), if they considered themselves knowledgeable about drug use (strongly agree/agree, disagree/strongly disagree), if using drugs is bad for a person's health (yes, no/don't know), if glue impairs a person's judgment (yes, no/don't know), if using glue can kill someone (yes, no/don't know), if using glue is addictive (yes, no/don't know), who taught them about drug use, if they cared about themselves and their health (strongly agree/agree, disagree/strongly disagree), if no one cared if they used drugs (strongly agree/agree, disagree/strongly disagree), if it's too hard to stop using drugs (strongly agree/agree, disagree/strongly disagree), if using drugs makes people "cool" (strongly agree/agree, disagree/strongly disagree), if they like how drugs make them feel (strongly agree/agree, disagree/strongly disagree), and if drugs make them feel powerful (strongly agree/agree, disagree/strongly disagree).

\section{Statistical Analysis}

Data were entered into Epi Info (3.5.1) from paper-based surveys and subsequently imported into SAS (version 9.0, Institute Inc, Cary, NC, USA) for analysis. Bivariate analysis using $\chi^{2}$ or Fisher's Exact Test (where expected cell sizes were less than 5) was used to test the associations between selected variables and the outcomes of interest. Multiple logistic regression analysis was used to identify independent covariates associated with lifetime and current drug use. Variables were selected for the model based on bivariate analyses significance $(\mathrm{p}<.05)$ and a theoretical model (Figure 1) conceptualizing factors associated with street-involved children and youth engaging in substance use. The Hosmer-Lemeshow goodness-of-fit test was utilized to assess the validity of the overall models.

\section{RESULTS}

There were 151 street-involved children and youth recruited; five were ineligible to participate in the study. There were therefore 146 children and youth aged 10-19 classified as either children on the street or children of the street enrolled to participate. Among these, $98(67 \%)$ were classified as children of the street and $48(33 \%)$ as children on the street. 


\section{Sociodemographic Characteristics}

Table 1 describes the detailed sociodemographic characteristics of all participants, stratified by classification of street-involved child and sex. Of particular note, males accounted for the majority of subjects in both categories (of the street: $85 \%$ and on the street: 65\%). The median age of the whole population was 14 years (interquartile range [IQR] 12-16); however, there were important differences between children on and of the street and males and females. Children on the street were on average younger than those of the street (median age 13 years vs. 14 years, $p=.03$ ). Female of the street youth were on average older (median age 16 years vs. 14 for boys, $p=.009$ ), and females on the street were on average younger than boys (median age 12 years vs. 13 for boys, $p=.97$ ). None of the participants had attended secondary school. Approximately $65 \%$ of youth were in contact with their family, but among those with any family contact, $30 \%$ had contact with them weekly or less often (59\% for children of the street). Most participants (79\%) indicated someone in their family used alcohol, tobacco, or other drugs, and this did not vary greatly among the two categories of youth or by sex. Among children of the street, $39 \%$ slept on the streets or in the barracks at night, while the majority (61\%) slept in communally rented shelters. Overall, $86 \%$ of children reported coming to the streets daily (fewer children on the street $(69 \%)$ than children of the street $(95 \%)$ ). While $42 \%$ of children reported having been street-involved for at least 2 years, another $40 \%$ reported having been on the street for less than 1 year. Almost all participants indicated they performed activities or work for money with the exception of girls on the street, whereby only 53\% reported engaging in income-generating activities. Most (57\%) children and youth reported earning less than 100 KES ( 1.00 USD) per day. Both males and females of the street reported that they accessed services for street children ( $83 \%$ and $93 \%$ ), whereas this was less commonly reported by males than by females on the street (58\% and 94\%, respectively).

\section{Substance Use Knowledge and Attitudes}

Participants' knowledge and attitudes about drug and substance use are summarized in detail in Table 2. Only 29\% $(n=42)$ of study subjects had ever been taught the dangers of using drugs, and $61 \%$ did not agree that they were knowledgeable about drug use. In general, males both of and on the street (33\% and 32\%, respectively) had received more education about the dangers of drug compared to the girls (13\% and $18 \%$ respectively). Despite the lack of education, nearly all (98\%) study subjects responded that using drugs is bad for a person's health, and many (67\%) agreed that they were aware of harms of using drugs. Additionally, most subjects responded that they thought using glue impaired a person's judgment (88\%), that using glue can kill someone (78\%) and that glue is addictive $(85 \%)$. Respondents most commonly reported learning about drugs from friends (62\%) followed by parents/guardians (16\%), and teachers (8\%). When querying about participants' attitudes, $95 \%$ of subjects strongly agreed or agreed that they care about themselves and their health, with all females in agreement. However, 53\% of children of the street felt that no one cared if they used drugs, whereas $81 \%$ of children on the street disagreed that no one cared if they used drugs. Nearly all subjects disagreed that using drugs makes people "cool" (93\%). Among participants who had used drugs, 64\% reported that they didn't like how drugs made them feel, and $73 \%$ reported that drugs did not make them feel powerful.

\section{Substance Use Practices}

Figure 2 illustrates the prevalence of lifetime and current substance use: $74 \%(n=108)$ of participants had any lifetime drug use, with $83 \%(n=81)$ of children of the street having ever used in comparison to only $56 \%(n=27)$ of children on the street. Of those classified as children of the street, $81 \%(n=67)$ of males and 93\% $(n=14)$ of females had any lifetime use; while, $65 \%(n=20)$ of males and $41 \%(n=7)$ of females on the street had any lifetime use. Eighty-three percent $(n=90)$ of participants who had ever used drugs were currently 
using. Similar proportions of males $(87 \%, n=58)$ and females $(79 \%, n=11)$ of the street reported current substance use, while $85 \%(n=17)$ of males and only $57 \%(n=4)$ of females on the street reported current use.

A total of 38 subjects reported never using drugs, of whom 63\% $(n=24)$ stated they had never used because they believed drugs were bad for their health, $21 \%(n=8)$ said that family and friends had told them drugs were bad, $16 \%(n=6)$ had other reasons. Similarly, for the 18 subjects who were not currently using drugs, $50 \%(n=9)$ stated they weren't using because drugs were bad for their health, $22 \%(n=4)$ said they didn't like how drugs made them feel, $17 \%(n=3)$ had other reasons, and $11 \%(n=2)$ said that their family and friends had told them drugs are bad.

Types of substances used are demonstrated in Figure 3 with their prevalence rates for lifetime and current use. The most commonly used substance among lifetime users was glue $(67 \%, n=98)$ followed by alcohol $(47 \%, n=69)$, cigarettes $(45 \%, n=65)$, miraa $(33 \%, n=$ $48)$, marijuana (29\%, $n=42)$, petrol $(24 \%, n=35)$, and pharmaceuticals $(8 \%, n=11)$. No participants admitted to ever using cocaine, heroin, or amphetamines. Similarly, the overwhelming majority of current users engaged in glue sniffing $(58 \%, n=85)$ followed by cigarettes $(21 \%, n=31)$, alcohol $(16 \%, n=24)$, marijuana $(11 \%, n=16)$, miraa $(7 \%, n=$ $10)$, petrol $(5 \%, n=7)$, and pharmaceuticals $(<1 \%, n=1)$. Of those currently engaging in glue use, $78 \%(n=66)$ reported using daily.

The median age of first trying any drugs was 11 years (IQR 9-13) and the median age of commencing to use regularly was 12 years (IQR 10-14). Most commonly, respondents identified friends ( $71 \%$ ) followed by family (18\%) as the person who introduced them to drugs. Participants' top five reasons for engaging in drug use were friends $(42 \%)$, forgetting their problems (32\%), to feel warmer (24\%), to feel good (17\%), and because they were addicted to them (14\%). Of those participants using substances daily, $60 \%$ spent less than 20 KES ( 0.20 USD) per day on drugs.

Only five (5\%) of lifetime users admitted to ever exchanging or selling sex to obtain drugs, while 29\% $(n=30)$ reported engaging in sexual activity while on drugs. Among these, 16\% $(n=17)$ reported having unprotected sex while using drugs.

Table 3 describes factors associated with lifetime and current substance use in both unadjusted and adjusted analyses. Multivariate analysis revealed that factors associated with having any lifetime drug use were increasing age (adjusted odds ratio $[\mathrm{AOR}]=1.47,95 \% \mathrm{CI}$ $=1.15-1.87$ ), having a family member who used alcohol, tobacco, or other drugs (AOR = $3.43,95 \% \mathrm{CI}=1.15-10.21)$, staying in a communally rented shelter $(\mathrm{AOR}=3.64,95 \% \mathrm{CI}=$ $1.13-11.73)$, and being street-involved for greater than 2 years $(\mathrm{AOR}=3.69,95 \% \mathrm{CI}=$ $1.22-11.18)$.

Factors independently associated with currently using drugs (vs. not currently and never) were: increasing age $(\mathrm{AOR}=1.28,95 \% \mathrm{CI}=1.06-1.54)$, family member alcohol, tobacco, or other drug use $(\mathrm{AOR}=2.73,95 \% \mathrm{CI}=1.10-6.80)$, and being street-involved for $1-2$ years $(\mathrm{AOR}=3.48,95 \% \mathrm{CI}=1.15-10.50)$ or greater than 2 years $(\mathrm{AOR}=3.33,95 \% \mathrm{CI}=$ $1.42-7.83)$.

\section{DISCUSSION}

Our findings highlight several key issues, which can inform public health policies and programs aimed at reducing substance use in this population. Specifically, that family members use of drugs and alcohol is consistently associated with the youth's use of substances combined with the small number of children and youth who reported having 
received any substance use education suggests a missed opportunity for education and sensitization. Differences between children of and on the street, age categories, and between males and females highlight the importance of creating targeted programs for at-risk groups, especially among older youth, and those who live in communal shelters. These are the subpopulations most likely to be currently using drugs and programs targeted at them, could achieve maximal impact because of this and because of their influence over younger children on the street.

While the overwhelming majority of children responded that they had never been taught the dangers of using drugs, many admitted to being aware of the harms of using and had a relatively strong knowledge about the detrimental effects of using glue. Consistent with our findings, research conducted elsewhere found that street boys described having a moderate degree of awareness about the negative health outcomes associated with their use, yet they continued to use inhalants (Cottrell-Boyce, 2010; Kaime-Atterhög \& Ahlberg, 2008; Morakinyo \& Odejide, 2003; Njord et al., 2010; Seth et al., 2005). In contrast, a study in Egypt reported that very few children acknowledged that using volatile substances could negatively impact health (Elkoussi \& Bakheet, 2011). Participants' heightened awareness and knowledge could be due to their personal and peer experiences with drug use; for example, friends were cited as the primary source for learning about drugs. Yet, even with what may be considered experiential knowledge, the overwhelming majority of participants still didn't consider themselves knowledgeable about drug use. This finding in combination with the fact that only a small number of children and youth reported having received any substance use education, demonstrates the importance of incorporating education and sensitization into interventions to mitigate substance use. Street children's drop-in programs and outreach activities in Eldoret should actively increase their substance use education programs and consider utilizing a community-based peer network of nonusers to disseminate information due to the strong influence peers play in street children's social networks.

The high prevalence of substance use found among street-involved children and youth in the present study is in line with findings from other resource-constrained settings (Adebiyi et al., 2008; Bal et al., 2010; Elkoussi \& Bakheet, 2011; Inciardi \& Surratt, 1998; Khurana et al., 2004; Kudrati et al., 2008; Morakinyo \& Odejide, 2003; Nada \& Suliman, 2010; Njord et al., 2010; Pagare et al., 2004; Sharma \& Lal, 2011; Sherman et al., 2005; Sorsa et al., 2002). A particularly concerning finding is the overwhelming use and dependence on glue. The pervasive use of glue and other inhalants has been reported in studies from Latin America, Africa, the Middle East, and Asia (Ayaya \& Esamai, 2001; Bal et al., 2010; Baldivieso, 1995; Carlini-Cotrim, 1995; Elkoussi \& Bakheet, 2011; Forster et al., 1996; Kudrati et al., 2008; Lerner \& Ferrando, 1995; Njord et al., 2010; Sharma \& Lal, 2011; Wittig et al., 1997). Cobblers are the primary source of glue distribution and sales for street children in Eldoret. Policymakers in Eldoret should consider regulating the sale of shoemaker's glue in order to reduce accessibility to the product by street youth. However, restricting access to volatile substances may result in a transition between products (Maclean \& D'Abbs, 2010) and has been ineffective in other locations unless accompanied by other programs that empower youth (MacLean \& d'Abbs, 2002). Therefore any policy aimed at restricting access to glue in Eldoret, should be accompanied by an increase in programs available through community-based organizations to create meaningful opportunities to empower and engage youth.

The differences between children of the street and children on the street and between males and females in our study merits discussion. Children of the street were the majority of lifetime and current users demonstrating the need to develop innovative interventions targeting rehabilitation, treatment, and prevention for substance use and homelessness; while, children on the street represent an at-risk population that should be targeted with up- 
stream community-based prevention efforts in the informal communities surrounding Eldoret to mitigate substance use or possible transitions from being children on the street to children of the street. Children on the street were significantly younger than those of the street and it is possible that as the duration of street-involvement increases so too does the risk of them engaging in substance use and full-time street life with increasing age. Interestingly, although not statistically significant, bivariate and multivariate analysis demonstrated a trend that girls were less likely than boys to be engaging in substance use. Girls $o f$ the street were on average older than their male counterparts, indicating perhaps that fewer young girls are becoming street-involved and homeless. A Brazilian study identified that families perceive that the streets are more dangerous for girls than boys, and therefore girls remain home to perform household duties, or are sent to work as house-help elsewhere, while boys become independent and are sent to the streets to bring home income for the family (Abdelgalil et al., 2004). It is likely that similar familial and social-cultural gender roles are influencing street-involvement for females and males in Kenya. While the proportion of girls in our sample size was small, these results may suggest that genderspecific harm reduction and prevention programs to reduce street-involvement and substance use may be valuable to address these differences.

Among the factors most strongly associated with lifetime and current use was spending nights in a communally rented shelter. While the act of communally renting a shelter may be a survival strategy to avoid police or violence on the streets at night, it is hypothesized that the social and peer influence of communal living adversely influences drug use. Qualitative work in Nairobi, Kenya, has uncovered the role glue sniffing plays in creating a social network and sense of belonging within street culture (Cottrell-Boyce, 2010) and many others have documented the role friends and peer pressure play in initiating and continual substance misuse (Bal et al., 2010; Fernandes \& Vaughn, 2008; Kudrati et al., 2008; Morakinyo \& Odejide, 2003; Seth et al., 2005). In order to mitigate the negative peer influence that augments substance use, programs should focus on collaborating with nonusing peers to become role models in the community, while considering working with policymakers to develop safe supervised shelter options for sleeping at night. Our finding that having a family member who uses alcohol, tobacco, or other drugs is strongly associated with lifetime and current drug use is important. It suggests that any prevention and/or rehabilitation program needs to engage families and communities about the "background" drug and alcohol use that appears to increase the odds of children using drugs themselves, at least among street-involved children and youth.

A cultural and community-based approach to prevention and treatment interventions for inhalant abuse has been central to programs targeting Aboriginal youth in Canada and Australia, and may have applicability to street children and youth in resource-constrained settings that face similar challenges. The use of inhalants by Aboriginal youth has been strongly tied with adverse socioeconomic conditions, loss of identity, and social and cultural dislocation. As well, it has been reported that the use of inhalants provides these youth with a sense of community and belonging (Cairney \& Dingwall, 2010; Coleman, Charles, \& Collins, 2001; Dell et al., 2011; Dingwall, Maruff, Clough, \& Cairney, 2011). The incorporation of traditional practices, cultural education, and interaction with elders, in combination with non-Aboriginal approaches to healing and harm reduction strategies within the social and cultural context of their respective communities has had a positive impact (Brady, 1995; Dell et al., 2011). Research into the applicability of utilizing cultural and community-based approaches to substance use interventions for street-involved children and youth in low-to-middle income countries requires further investigation, yet may provide a valuable approach to rehabilitation. Due to the complex cultural and community systems present in Kenya and the differences present among children in this study, a multifaceted community-based and directed intervention should be developed. Relevant stakeholders, 
policymakers, community members, and the children themselves should be involved in directing and developing a comprehensive intervention strategy.

\section{Study's Strengths and Limitations}

This study has several strengths. First, it is one of the only studies to describe the knowledge and attitudes of street children toward substance use and evaluate how they relate to substance use practices. Second, we were able to highlight the differences among the on and of the street youth that may assist in creating targeted interventions. Finally, few studies have managed to recruit and enroll street-involved girls; our study included 32 girls on and $o f$ the street, and was able to describe the gender differences for drug use knowledge, attitudes, and practices among children in street circumstances.

This study also has limitations. The nonrandom recruitment and sampling of participants through active outreach and a snowball sampling technique is prone to selection bias. Children and youth who self-selected to participate through snowball sampling and those who accepted to participate versus declined through active outreach could be systematically different. To limit the effects of selection bias, outreach and study sensitization was performed in all areas of Eldoret where street children and youth are found in an attempt to obtain a representative sample generalizable to the population. Furthermore, social desirability bias could have affected responses to sensitive questions about drug use knowledge, attitudes, and practices. Children may have responded to questions about drugs with answers that they believed the interviewer wanted to hear. Differential recall bias may have affected responses to sociodemographic characteristics and drug use questions depending on the length of time a child has been streetinvolved, the classification of street child, and depending on their substance use habits altering their ability to remember events. Finally, the cross-sectional nature of this investigation limits the ability to draw causal inferences.

\section{CONCLUSION}

Overall, these findings have major implications for the development of interventions for street-involved children and youth in Kenya and other resource-constrained settings. These results demonstrate the urgent need to develop effective and innovative interventions for children in street circumstances to mitigate the harmful effects of long-term substance use and street life. In Kenya, there is a need to develop evidenced-based policy and programs targeting street children and youth with increased collaboration between policymakers, researchers, stakeholders, and community members. This investigation worked with the local District Children's Officer to protect and uphold the rights of children in the County and plans to disseminate findings to the local administration, relevant stakeholders, and the National Campaign Against Drug Abuse (NACADA) Authority in order to help shape policy interventions. Any intervention and rehabilitation strategy developed needs to address the wider socioeconomic issues, as well as the cultural and community contexts in which these children find themselves struggling to survive.

\section{Acknowledgments}

The project described was supported in part by Award Number R01HD060478 from the Eunice Kennedy Shriver National Institute Of Child Health \& Human Development. The content is solely the responsibility of the authors and does not necessarily represent the official views of the Eunice Kennedy Shriver National Institute of Child Health \& Human Development or the National Institutes of Health.

We would like to acknowledge Isaac Mwaniki for his assistance as a social worker, for administering the survey in Kiswahili, and for his outreach work in association with Dominic Makori. We would also like to acknowledge the OSCAR study staff and MTRH for providing healthcare services and support to children requiring or requesting 
care. We acknowledge the District Children's Officer, Mr. Philip Nzenge, for protecting and upholding the rights of children in the Uasin Gishu County and his approval for this study to proceed.

\section{Biographies}

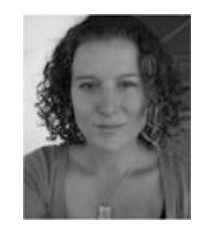

Lonnie Embleton, MPH, is an epidemiologist holding a Master of Public Health from the University of Toronto. Lonnie completed an undergraduate degree in Community Health Sciences from Brock University as well as a bachelor's degree from Ryerson University in Architectural Science. She is currently living and working in Eldoret, Kenya, where her research work focuses on orphans and street-involved children and youth in resourceconstrained settings.

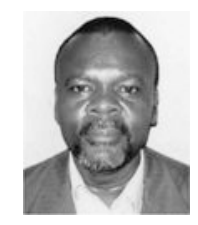

Dr. David Ayuku, PhD, is an Associate Professor Associate Professor of Clinical Psychology, in the Department of Behavioral Sciences, at Moi University, School of Medicine. He completed a PhD in Clinical Psychology with a focus on street children in Eldoret, Kenya. He is a member of the Kenya Association of Professional Counsellors and the Kenya Psychiatric Association.

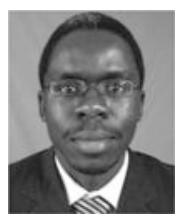

Dr. Lukoye Atwoli, M.B. Ch.B., M.Med. Psych., is a Mental Health Specialist (consultant psychiatrist) at the Moi Teaching and Referral Hospital in Eldoret, Kenya. He is also a lecturer at Moi University School of Medicine, Department of Mental Health, where he is involved in teaching medical students and conducting research. He has research interests in trauma, general hospital psychiatry, substance use, and research methodology in mental health.

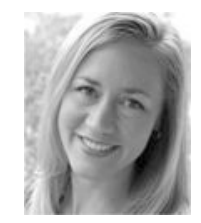

Rachel C. Vreeman, MD, MS, is an assistant professor of pediatrics in the Children's Health Services Research program and in the division of Pediatric Infectious Diseases at the Indiana University School of Medicine. In addition, she is codirector of pediatric research for the Indiana University-Kenya Partnership and the Academic Model Providing Access to Healthcare (AMPATH) partnership, which provides comprehensive HIV treatment for 
over 130,000 patients in Kenya. Dr. Vreeman's research work focuses on improving the provision of healthcare to children within resource-limited settings.

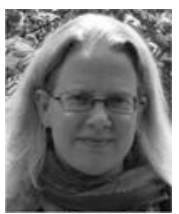

Paula Braitstein, MA, MSc, PhD, is an epidemiologist living and working in Eldoret, Kenya, with Moi University School of Medicine, Moi Teaching and Referral Hospital, and the USAID-Academic Model Providing Access To Healthcare (AMPATH) Partnership. Originally from Montreal, Paula spent 13 years working in the communitybased HIV/AIDS movement in Canada as an HIV treatment educator and activist. After receiving her MA in Liberal Studies from Simon Fraser University, Paula completed both an MSc and a PhD in epidemiology from the University of British Columbia and went on to do her postdoctoral research in Bern, Switzerland, working with the Antiretroviral Treatment in Lower Income Countries (ART-LINC) Collaboration conducting multicenter observational analyses of the effectiveness of antiretroviral treatment in low- and middle-income countries. Paula has published widely in the peer-reviewed literature on diverse topics. Her research foci today are concentrated on vulnerable and marginalized children in sub-Saharan Africa, including orphans, street-involved children and youth, HIV-infected and affected children, and the mental and reproductive health issues of adolescents.

\section{REFERENCES}

Abdelgalil S, Gurgel RG, Theobald S, Cuevas LE. Household and family characteristics of street children in Aracaju, Brazil. Archives of Diseases in Childhood. 2004; 89(9):817-820. [PubMed: 15321855]

Adebiyi A, Owaoje O, Asuzu M. Relationships as determinants of substance use amongst street children in local government area in south-western Nigeria. South African Family Practice. 2008; 50(5):47-47d.

Ayaya SO, Esamai FO. Health problems of street children in Eldoret, Kenya. East African Medical Journal. 2001; 78(12):624-629. [PubMed: 12199442]

Ayuku D, Ettyang G, Odero W. Psychosocial and nutritional status of street children in comparison to school children: A case of Eldoret town. African Journal of Food, Agriculture, Nutrition, Development. 2004; 4(1):1-11.

Ayuku D, Kaplan CD, Baars HMJ, de Vries MW. Characteristics and personal social networks of the "on" the street, "of" the street, shelter and school children in Eldoret, Kenya. International Social Work. 2004; 47(3):293-311.

Ayuku D, Odero W, Kaplan C, De Bruyn R, De Vries M. Social network analysis for health and social interventions among Kenyan scavenging street children. Health Policy Plan. 2003; 18(1):109-118. [PubMed: 12582114]

Ayuku DO, Devries MW, Mengech HN, Kaplan CD. Temperament characteristics of street and nonstreet children in Eldoret, Kenya. African Health Sciences. 2004; 4(1):24-30. [PubMed: 15126189]

Bal B, Mitra R, Mallick AH, Chakraborti S, Sarkar K. Nontobacco substance use, sexual abuse, HIV, and sexually transmitted infection among street children in Kolkata, India. Substance Use Misuse. 2010; 45(10):1668-1682. [PubMed: 20590379]

Baldivieso LE. Inhalant abuse in Bolivia. NIDA Research Monograph. 1995; 148:50-63. [PubMed: 8929884]

Brady M. Culture in treatment, culture as treatment. A critical appraisal of developments in addictions programs for indigenous North Americans and Australians. Social Science \& Medicine. 1995; 41(11):1487-1498. [PubMed: 8607039] 
Cairney S, Dingwall K. The mysterious practice of petrol sniffing in isolated indigenous groups. The Journal of Paediatrics and Child Health. 2010; 46(9):510-515.

Carlini-Cotrim B. Inhalant use among Brazilian youths. NIDA Research Monograph. 1995; 148:6478. [PubMed: 8929885]

Coleman H, Charles G, Collins J. Inhalant use by Canadian aboriginal youth. Journal of Child and Adolescent Substane Abuse. 2001; 10(3):1-20.

Cottrell-Boyce J. The role of solvents in the lives of Kenyan street children: An ethnographic perspective. African Journal of Drug and Alcohol Studies. 2010; 9(2):93-102.

de Carvalho FT, Neiva-Silva L, Ramos MC, Evans J, Roller SH, Piccinini CA, et al. Sexual and drug use risk behaviors among children and youth in street circumstances in Porto Alegre, Brazil. AIDS Behavior. 2006; 10(4 Suppl.):S57-S66. [PubMed: 16845605]

Dell CA, Seguin M, Hopkins C, Tempier R, Mehl-Madrona L, Dell D, et al. From benzos to berries: Treatment offered at an Aboriginal youth solvent abuse treatment centre relays the importance of culture. Canadian Journal of Psychiatry. 2011; 56(2):75-83.

Dingwall KM, Maruff P, Clough AR, Cairney S. Factors associated with continued solvent use in indigenous petrol sniffers following treatment. Drug and Alcohol Review. 2011; 31(1):40-46. [PubMed: 21355931]

Einterz RM, Kimaiyo S, Mengech HN, Khwa-Otsyula BO, Esamai F, Quigley E, et al. Responding to the HIV pandemic: The power of an academic medical partnership. Academy of Medicine. 2007; 82(8):812-818.

Elkoussi A, Bakheet S. Volatile substance misuse among street children in Upper Egypt. Substance Use Misuse. 2011; 46(1 Suppl):35-39. [PubMed: 21609143]

Fernandes GT, Vaughn MG. Brazilian street children: Contextual influences in relation to substance misuse. International Social Work. 2008; 51(5):669-681.

Forster LM, Tannhauser M, Barros HM. Drug use among street children in southern Brazil. Drug and Alcohol Dependence. 1996; 43(1-2):57-62. [PubMed: 8957143]

Gaidhane A, Zahiruddin QS, Waghmare L, Shanbhag S, Zodpey S, Joharapurkar SR. Substance abuse amongst street children in Mumbai. Vulnerable Children and Youth Studies. 2008; 3(1):42-51.

Inciardi JA, Surratt HL. Children in the streets of Brazil: Drug use, crime, violence, and HIV risks. Substance Use Misuse. 1998; 33(1):1461-1480. [PubMed: 9657412]

IRIN. Youth in crisis: Coming of age in the 21st century. 2007. Retrieved June 21, 2012, from http:// www.irinnews.org/In-Depth/70140/28/Youth-in-crisis-Coming-of-age-in-the-21st-century

Kaime-Atterhog W, Ahlberg BM. Are street children beyond rehabilitation? Understanding the life situation of street boys through ethnographic methods in Nakuru, Kenya. Children and Youth Services Review. 2008; 30(12):1345-1354.

Khurana S, Sharma M, Jena S, Saha R, Ingle GK. Mental health status of runaway adolescents. Indian Journal of Pediatrics. 2004; 71(5):405-409. [PubMed: 15163868]

Kudrati M, Plummer ML, Yousif ND. Children of the sug: A study of the daily lives of street children in Khartoum, Sudan, with intervention recommendations. Child Abuse \& Neglect. 2008; 32(4): 439-448. [PubMed: 18457872]

Kurtzman T, Otsuka K, Wahl R. Inhalant abuse by adolescents. Journal of Adolescent Health. 2001; 28:170-180. [PubMed: 11226839]

le Roux J. The worldwide phenomenon of street children: Conceptual analysis. Adolescence. 1996; 31(124):965-971. [PubMed: 8970667]

Lerner R, Ferrando D. Inhalants in Peru. NIDA Research Monograph. 1995; 148:191-204. [PubMed: 8929891]

MacLean SJ, d'Abbs PH. Petrol sniffing in Aboriginal communities: A review of interventions. Drug and Alcohol Reveiw. 2002; 21(1):65-72.

Maclean SJ, D' Abbs PH. Five challenges for volatile substance misuse policy and intervention in Australia. Drug and Alcohol Reveiw. 2010; 30(2):223-227.

Monde, Md. Data collection: The KAP survey model. Medicins du Monde; 2011. 
Morakinyo J, Odejide AO. A community based study of patterns of psychoactive substance use among street children in a local government area of Nigeria. Drug and Alcohol Dependence. 2003; 71(2): 109-116. [PubMed: 12927648]

Nada KH, Suliman EDA. Violence, abuse, alcohol and drug use, and sexual behaviors in street children of Greater Cairo and Alexandria, Egypt. AIDS. 2010; 24(2 Suppl.):S39-S44. [PubMed: 20610947]

Njord L, Merrill RM, Njord R, Lindsay R, Pachano JD. Drug use among street children and non-street children in the Philippines. Asia-Pacific Journal of Public Health. 2010; 22(2):203-211. [PubMed: 20457649]

Pagare D, Meena GS, Singh MM, Saha R. Risk factors of substance use among street children from Delhi. Indian Pediatrics. 2004; 41(3):221-225. [PubMed: 15064508]

Plummer ML, Kudrati M, Dafalla El Hag, Yousif N. Beginning street life: Factors contributing to children working and living on the streets of Khartoum, Sudan. Child and Youth Services Review. 2007; 29(12):1520-1536.

Project, KOD. Kenya open data project. 2011. Retrieved February, 12, 2012, from http:// opendata.go.ke/

Seth R, Kotwal A, Ganguly KK. Street and working children of Delhi, India, misusing toluene: An ethnographic exploration. Substance Use Misuse. 2005; 40(11):1659-1679. [PubMed: 16253933]

Sharma S, Lal R. Volatile substance misuse among street children in India: A preliminary report. Substance Use Misuse. 2011; 46(1 Suppl):46-49. [PubMed: 21609145]

Sherman SS, Plitt S, ul Hassan S, Cheng Y, Zafar ST. Drug use, street survival, and risk behaviors among street children in Lahore, Pakistan. The Journal of Urban Health. 2005; 82(3 Suppl. 4):ivl13-iv124.

Sorsa S, Kidanemariam T, Erosie L. Health problems of street children and women in Awassa, Southern Ethiopia. The Ethiopian Journal of Health Development. 2002; 16(2):129-137.

Towe VL, ul Hasan S, Zafar ST, Sherman SG. Street life and drug risk behaviors associated with exchanging sex among male street children in Lahore, Pakistan. The Journal of Adolescent Health. 2009; 44(3):222-228. [PubMed: 19237107]

UNHABITAT. The State of African Cities: A framework for addressing urban challenges in Africa. Nairobi, Kenya: United Nations Human Settlements Programme; 2008.

UNICEF. The state of the World's children 2006: Excluded and invisible. New York: Author; 2006.

Von Acker J, Oosrrom D, Rorh B, De Kemp R. Street children in Nairobi: Hakuna Matata? Journal of Community Psychology. 1999; 27(4):393-104.

WHO. Advocacy, communication and social mobilization for TB control: A guide to developing knowledge, attitudes and practices surveys. Geneva, Switzerland: World Health Organization; 2008.

Wittig MC, Wright JD, Kaminsky DC. Substance use among street children in Honduras. Substance Use Misuse. 1997; 32(7-8):805-827. [PubMed: 9220558] 


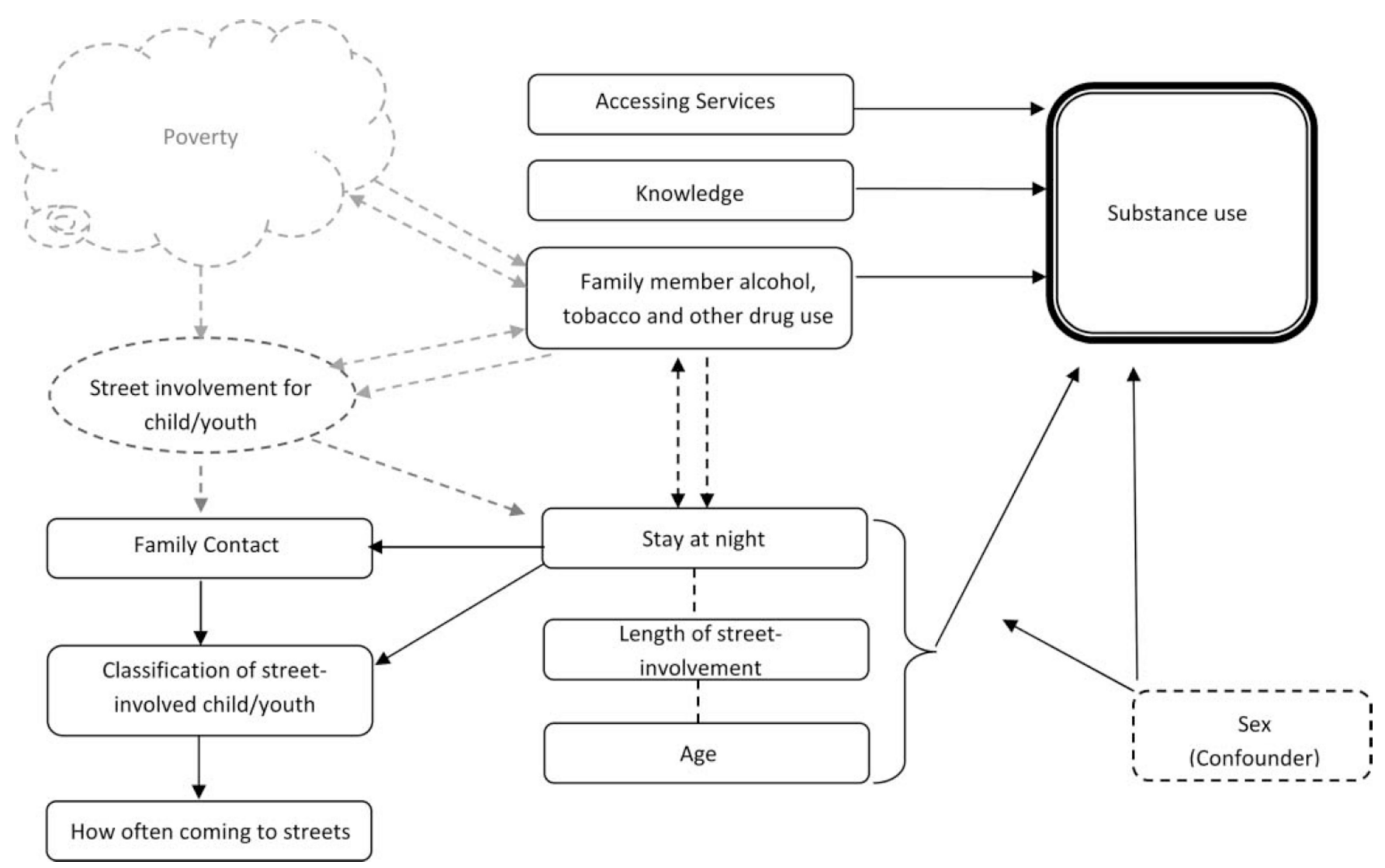

FIGURE 1.

Conceptual model of factors associated with street children's drug use. 


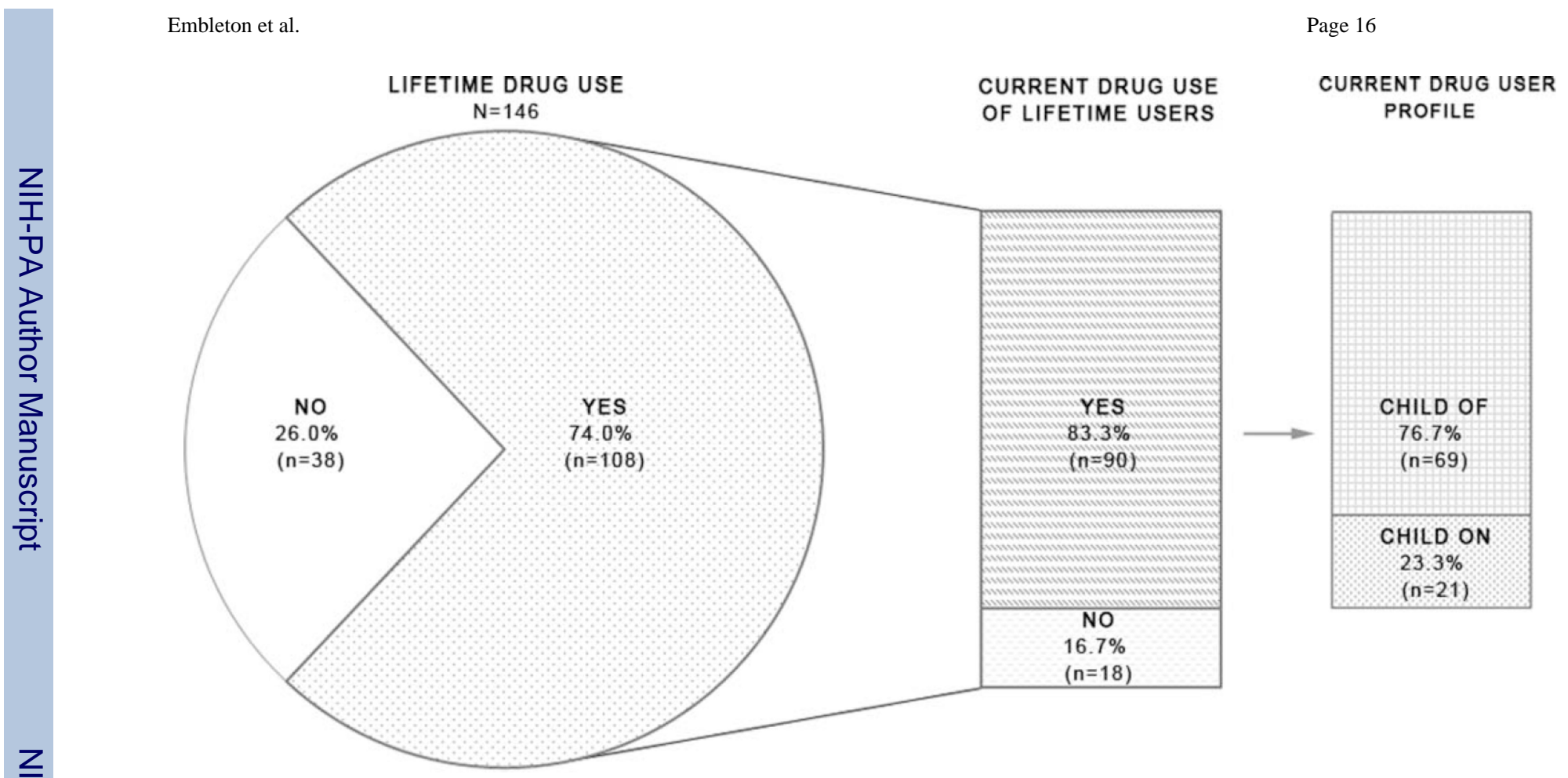

FIGURE 2.

Prevalence of lifetime and current substance use among 146 street-involved children and youth in Eldoret, Kenya. 


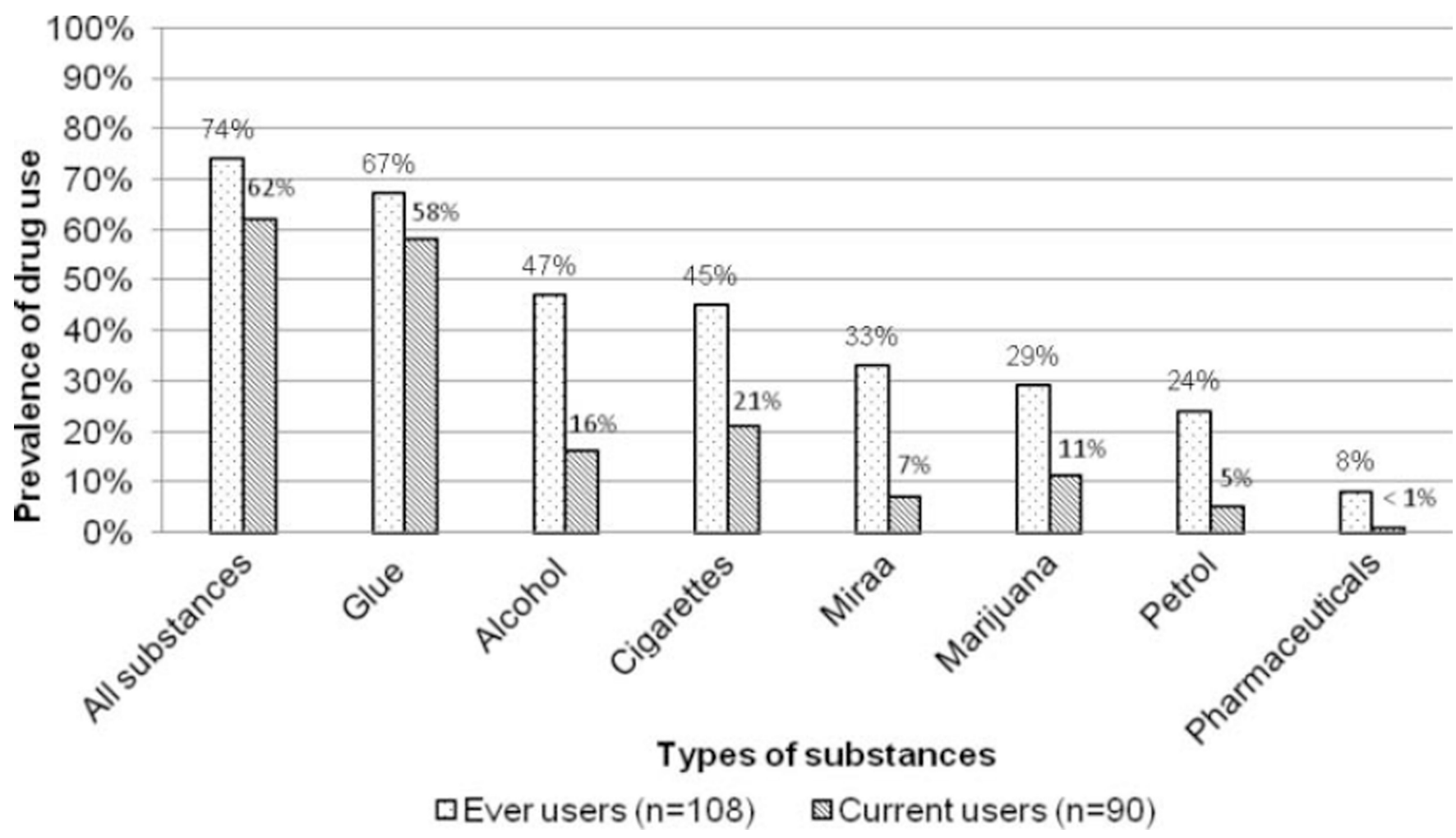

FIGURE 3.

Prevalence of substances used by lifetime and current users. 


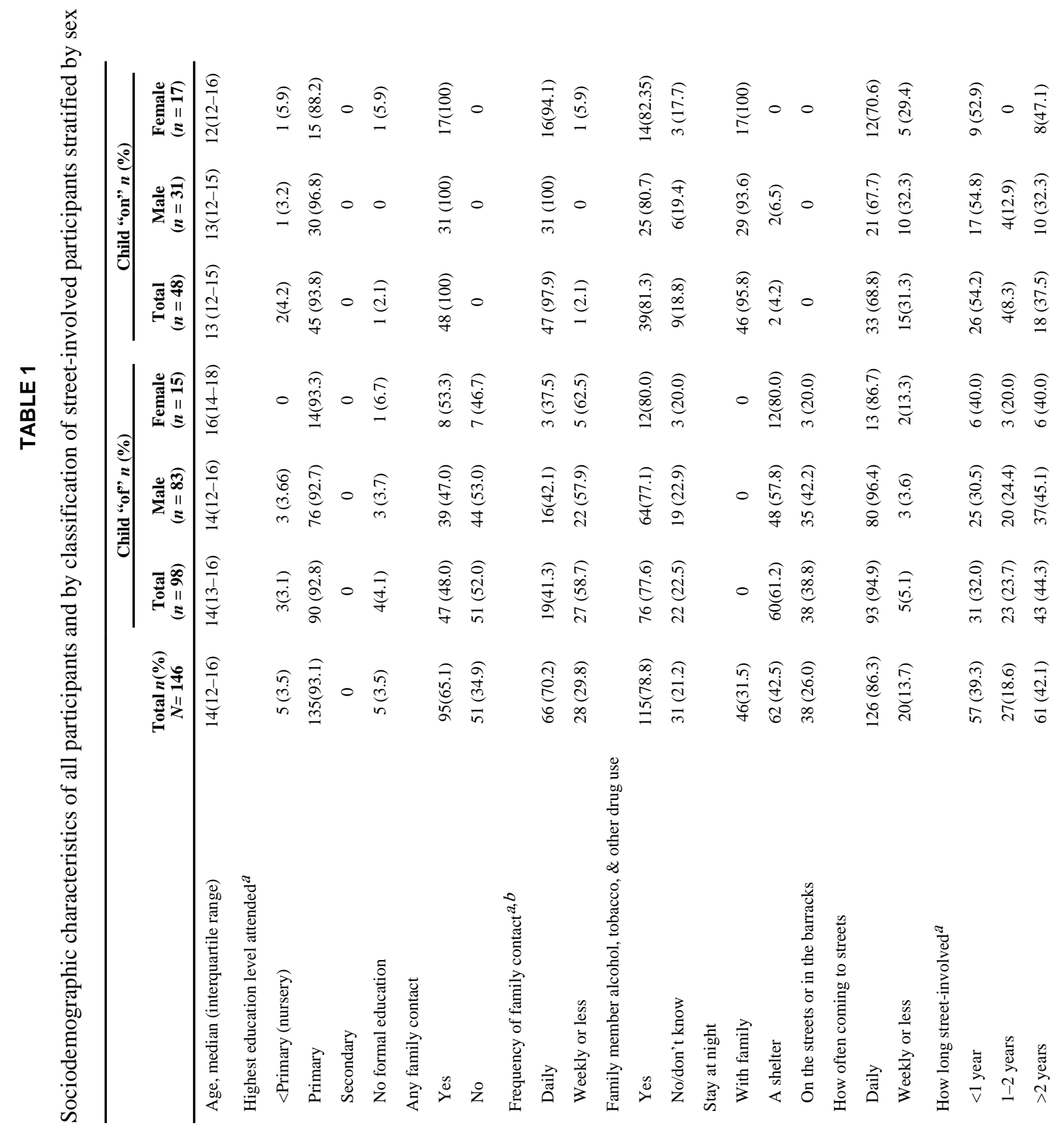


Embleton et al.

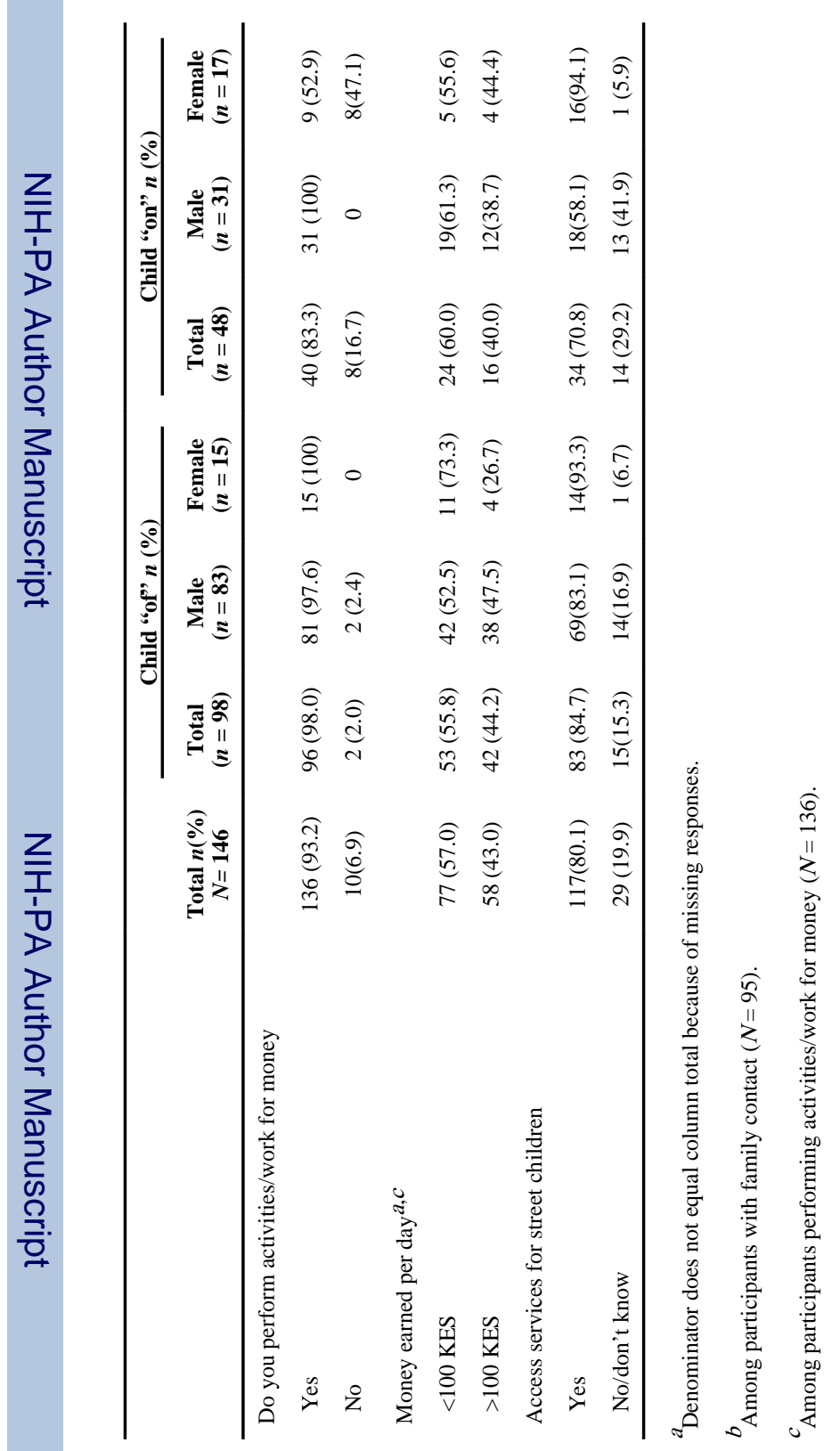

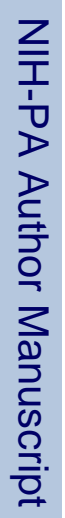




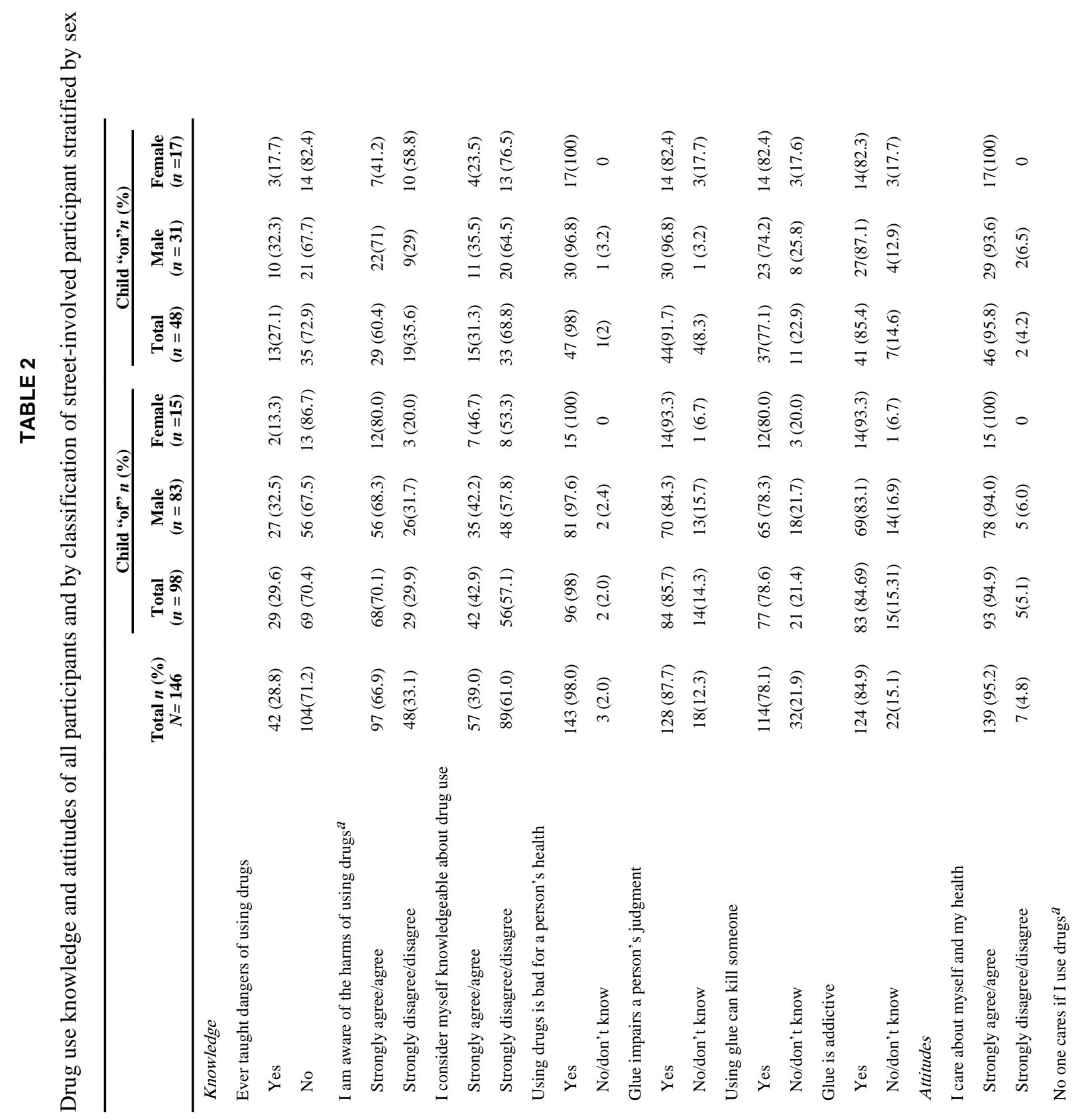


Embleton et al.

Page 21

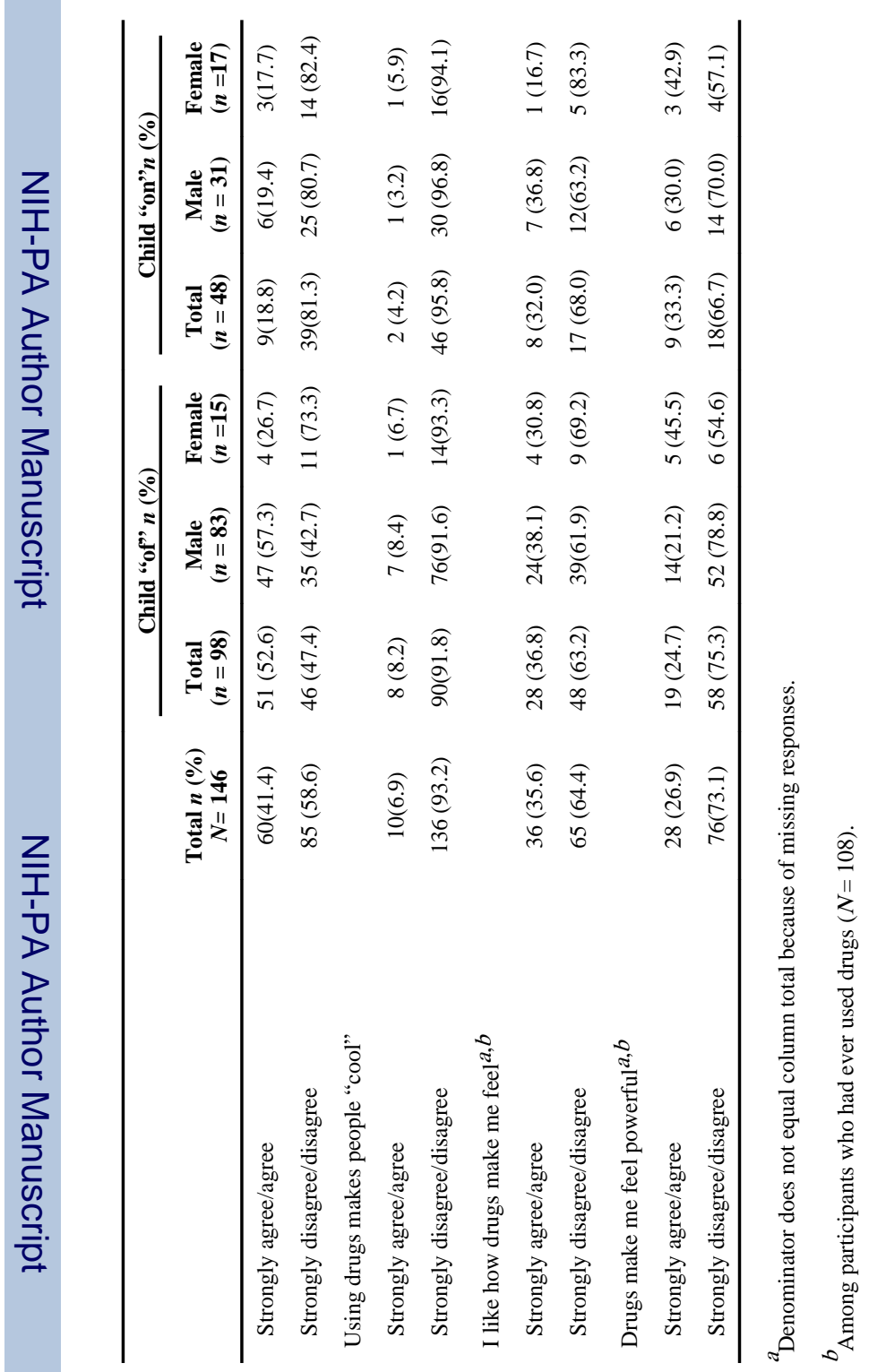

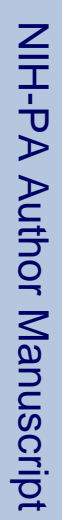

Subst Use Misuse. Author manuscript; available in PMC 2013 August 22. 
TABLE 3

Unadjusted and adjusted odds ratios (OR) and 95\% confidence intervals (CI) of factors associated with lifetime and current substance use

\begin{tabular}{|c|c|c|c|c|}
\hline & $\begin{array}{c}\text { Lifetime versus } \\
\text { never use } \\
\text { Unadjusted } \\
\text { OR }(95 \% \text { CI })\end{array}$ & $\begin{array}{l}\text { Lifetime versus } \\
\text { never use } \\
\text { Adjusted }{ }^{* *} \\
\text { OR (95\% CI) }\end{array}$ & $\begin{array}{c}\text { Current versus } \\
\text { never/not } \\
\text { current Unadjusted } \\
\text { OR }(95 \% \text { CI })\end{array}$ & $\begin{array}{c}\text { Current versus } \\
\text { never/not } \\
\text { current Adjusted } \\
\text { OR }(95 \% \mathrm{CI})\end{array}$ \\
\hline Age (per year increase) & $1.55(1.26-1.91)$ & $1.47(1.15-1.87)$ & $1.29(1.11-1.51)$ & $1.28(1.06-1.54)$ \\
\hline \multicolumn{5}{|l|}{ Sex } \\
\hline Male & 1.0 & 1.0 & 1.0 & 1.0 \\
\hline Female & $0.59(0.25-1.38)$ & $0.33(0.10-1.13)$ & $0.46(0.21-1.02)$ & $0.39(0.14-1.06)$ \\
\hline \multicolumn{5}{|l|}{ Education level } \\
\hline$<$ Primary (nursery) & $0.52(0.08-3.24)$ & - & $0.41(0.07-2.55)$ & - \\
\hline Primary & 1.0 & - & 1.0 & - \\
\hline No formal education & $1.39(0.15-12.8)$ & - & $2.48(0.27-22.76)$ & - \\
\hline \multicolumn{5}{|c|}{ Classification of street-involved child/youth } \\
\hline Child of the street & $3.71(1.71-8.03)$ & - & $3.06(1.49-6.26)$ & - \\
\hline Child on the street & 1.0 & - & 1.0 & - \\
\hline \multicolumn{5}{|l|}{ Any family contact } \\
\hline Yes & $0.33(0.13-0.81)$ & - & $0.55(0.27-1.13)$ & - \\
\hline No & 1.0 & - & 1.0 & - \\
\hline \multicolumn{5}{|l|}{ Frequency of family contact } \\
\hline Daily & $0.36(0.12-1.06)$ & - & $0.43(0.16-1.10)$ & - \\
\hline Weekly or less & 1.0 & - & 1.0 & - \\
\hline \multicolumn{5}{|c|}{ Family member alcohol, tobacco, and drug use } \\
\hline Yes & $2.16(0.93-5.03)$ & $3.43(1.15-10.21)$ & $2.37(1.06-5.30)$ & $2.73(1.10-6.80)$ \\
\hline No & 1.0 & 1.0 & 1.0 & 1.0 \\
\hline \multicolumn{5}{|l|}{ Stay at night } \\
\hline With family & 1.00 & 1.0 & 1.0 & 1.0 \\
\hline A shelter & $5.67(2.21-14.55)$ & $3.64(1.13-11.73)$ & $3.18(1.43-7.07)$ & $1.99(0.78-5.07)$ \\
\hline On the streets or in the barracks & $2.71(1.05-6.97)$ & $1.47(0.45-4.77)$ & $2.82(1.15-6.92)$ & $2.11(0.76-5.89)$ \\
\hline \multicolumn{5}{|l|}{ How often coming to streets } \\
\hline Daily & $2.74(1.03-7.25)$ & - & $3.59(1.33-9.65)$ & - \\
\hline Weekly or less & 1.00 & - & 1.0 & - \\
\hline \multicolumn{5}{|l|}{ How long street involved? } \\
\hline$<1$ year & 1.00 & 1.0 & 1.0 & 1.0 \\
\hline $1-2$ years & $2.65(0.93-7.54)$ & $1.90(0.53-6.83)$ & $4.05(1.48-11.08)$ & $3.48(1.15-10.50)$ \\
\hline$>2$ years & $5.84(2.28-15.01)$ & $3.69(1.22-11.18)$ & $4.34(1.99-9.50)$ & $3.33(1.42-7.83)$ \\
\hline \multicolumn{5}{|l|}{ Access services for street children } \\
\hline Yes & $2.99(1.27-7.03)$ & $2.08(0.68-6.36)$ & $1.99(0.87-4.52)$ & - \\
\hline No & 1.00 & 1.0 & 1.0 & - \\
\hline \multicolumn{5}{|l|}{ Ever taught dangers of using drugs } \\
\hline Yes & $0.99(0.44-2.23)$ & - & $1.02(0.49-2.12)$ & - \\
\hline No & 1.0 & - & 1.0 & - \\
\hline
\end{tabular}




\begin{tabular}{|c|c|c|c|c|}
\hline & $\begin{array}{c}\text { Lifetime versus } \\
\text { never use } \\
\text { Unadjusted } \\
\text { OR }(95 \% \mathrm{CI})\end{array}$ & $\begin{array}{c}\text { Lifetime versus } \\
\text { never use } \\
\text { Adjusted } \\
\text { OR }(95 \% \text { CI })\end{array}$ & $\begin{array}{c}\text { Current versus } \\
\text { never/not } \\
\text { current Unadjusted } \\
\text { OR }(95 \% \text { CI })\end{array}$ & $\begin{array}{c}\text { Current versus } \\
\text { never/not } \\
\text { current Adjusted } \\
\text { OR }(95 \% \text { CI })\end{array}$ \\
\hline \multicolumn{5}{|c|}{ I am aware of the harms of using drugs } \\
\hline Strongly agree/agree & $1.99(0.93-4.26)$ & - & $1.27(0.62-2.57)$ & - \\
\hline Strongly disagree/disagree & 1.0 & - & 1.0 & - \\
\hline \multicolumn{5}{|l|}{ No one cares if I use drugs } \\
\hline Strongly agree/agree & $1.76(0.81-3.86)$ & - & $1.24(0.62-2.46)$ & - \\
\hline Strongly disagree/disagree & 1.0 & - & 1.0 & - \\
\hline \multicolumn{5}{|c|}{ I consider myself knowledgeable about drug use } \\
\hline Strongly agree/agree & $1.13(0.53-2.43)$ & - & $1.42(0.71-2.85)$ & - \\
\hline Strongly disagree/disagree & 1.0 & - & 1.0 & - \\
\hline \multicolumn{5}{|c|}{ Glue impairs a person's judgment } \\
\hline Yes & $0.15(0.02-1.13)^{*}$ & $0.11(0.01-1.02)$ & $0.42(0.13-1.34)$ & - \\
\hline No & 1.0 & 1.0 & 1.0 & - \\
\hline \multicolumn{5}{|l|}{ Using glue can kill someone } \\
\hline Yes & $2.03(0.88-4.70)$ & - & $2.57(1.16-5.72)$ & - \\
\hline No & 1.0 & - & 1.0 & - \\
\hline \multicolumn{5}{|l|}{ Glue is addictive } \\
\hline Yes & $2.27(0.88-5.84)$ & - & $1.41(0.57-3.53)$ & - \\
\hline No & 1.0 & - & 1.0 & - \\
\hline \multicolumn{5}{|l|}{ Money earned per day } \\
\hline$<100 \mathrm{KES}$ & $0.86(0.37-1.95)$ & - & $0.98(0.48-1.99)$ & - \\
\hline$>100 \mathrm{KES}$ & 1.0 & - & 1.0 & - \\
\hline \multicolumn{5}{|l|}{ I like how drugs make me feel } \\
\hline Strongly agree/agree & - & - & $0.75(0.22-2.55)$ & - \\
\hline Strongly disagree/disagree & - & - & 1.0 & - \\
\hline \multicolumn{5}{|l|}{ Drugs make me feel powerful } \\
\hline Strongly agree/agree & - & - & $1.41(0.36-5.48)$ & - \\
\hline Strongly disagree/disagree & - & - & 1.0 & - \\
\hline \multicolumn{5}{|c|}{ Using drugs make people "cool" } \\
\hline Strongly agree/agree & - & - & $1.49(0.37-6.02)$ & - \\
\hline Strongly disagree/disagree & - & - & 1.0 & - \\
\hline \multicolumn{5}{|c|}{ Ever engaged in sexual activity on drugs } \\
\hline Yes & - & - & $2.94(0.62-13.89)$ & - \\
\hline No & - & - & 1.0 & - \\
\hline \multicolumn{5}{|c|}{ Ever engaged in unprotected sex on drugs } \\
\hline Yes & - & - & $1.30(0.27-6.37)$ & - \\
\hline No & - & - & 1.0 & - \\
\hline \multicolumn{5}{|l|}{ Fisher's exact test $p=.0426$} \\
\hline
\end{tabular}

